\title{
Identification of nanostructural development in epoxy polymer layered silicate nanocomposites from the interpretation of differential scanning calorimetry and dielectric spectroscopy
}

\author{
Frida Román, Yolanda Calventus, Pere Colomer, John M. Hutchinson* \\ Laboratori de Termodinàmica, Departament de Màquines i Motors Tèrmics, ETSEIAT, Universitat Politècnica de Catalunya, Carrer Colom 11, 08222 Terrassa, Spain
}

\section{A R T I C L E I N F O}

\section{Article history:}

Received 27 January 2012

Received in revised form 25 April 2012

Accepted 1 May 2012

Available online 8 May 2012

\section{Keywords:}

Cure kinetics

Differential scanning calorimetry (DSC)

Dielectric spectroscopy

Epoxy

Glass transition

Nanocomposites

\begin{abstract}
A B S T R A C T
The effect of nanoclay on the non-isothermal cure kinetics of polymer layered silicate nanocomposites based upon epoxy resin is studied by calorimetric techniques (DSC and TGA) and by dielectric relaxation spectroscopy (DRS) in non-isothermal cure at constant heating rate. The cure process takes place by homopolymerisation, initiated anionically using $3 \mathrm{wt} \%$ dimethylaminopyridine (DMAP), and the influence of the nanoclay content has been analysed. Interesting differences are observed between the nanocomposites with $2 \mathrm{wt} \%$ and $5 \mathrm{wt} \%$ clay content. At low heating rates, these samples vitrify and then devitrify during the cure. For the sample with $2 \mathrm{wt} \%$ clay, the devitrification is accompanied by a thermally initiated homopolymerisation, which can be identified by DRS but not by DSC. The effect of this is to improve the exfoliation of the nanocomposite with $2 \mathrm{wt} \%$ clay, as verified by transmission electron microscopy, with a corresponding increase in the glass transition temperature. These observations are interpreted in respect of the nanocomposite preparation method and the cure kinetics.
\end{abstract}

(C) 2012 Elsevier B.V. All rights reserved.

\section{Introduction}

The field of nanotechnology is one of the most popular areas for current research and development in basically all technical disciplines. This obviously includes polymer science and technology, and even within this limited field the investigations cover a broad range of topics. The main areas of application are nanoelectronics (critical dimension scales for modern devices are now below $100 \mathrm{~nm}$ ), polymer-based biomaterials, fuel cell electrode polymer-bound catalysts, layer-by-layer self-assembled polymer films, electrospun nanofibres, imprint lithography, polymer blends and nanocomposites [1]. Polymer layered silicate (PLS) nanocomposites are of particular interest because of their demonstrated improvements, relative to an unmodified resin, which in the present case is an epoxy resin. These improvements apply to a wide range of properties, and especially mechanical properties (modulus, strength, toughness), physical properties such as the thermal expansion coefficient, barrier properties, fire resistance, ablation performance and environmental stability [2,3].

The fabrication of such nanocomposites, and in particular those based upon epoxy resin, follows the in situ polymerisation route,

\footnotetext{
* Corresponding author. Tel.: +34 93739 8123; fax: +34 937398101

E-mail addresses: roman@mmt.upc.edu (F. Román), calventus@mmt.upc.edu (Y. Calventus), colomer@mmt.upc.edu (P. Colomer), hutchinson@mmt.upc.edu (J.M. Hutchinson)
}

which involves a sequence of stages. First, the epoxy resin is mixed with the required amount of organically modified clay, in the course of which the resin penetrates into the galleries between the silicate layers in a process known as intercalation. Next, the required amount of cross-linking agent is added to the resin-clay mixture and the system is subjected to a cure schedule in order to achieve a fully cured nanocomposite, in which the clay layers are, in the ideal situation, fully exfoliated [4-7].

The nanostructure and properties of the final product can depend significantly on the details associated with each of the stages in the fabrication process. Optimum properties of the nanocomposite are obtained only if the silicate layers are exfoliated and homogeneously distributed throughout the cross-linked epoxy matrix. In practice, what is often likely to occur is a combination of three morphologies, namely a phase-separated microcomposite, an intercalated nanocomposite and an exfoliated nanocomposite, with the optimum situation being when the last of these is dominant.

The mechanisms by which exfoliation occurs are not well defined. The exfoliation is influenced by a variety of factors, including the organic modification of the clay, the resin type, the curing agent, the procedure for mixing the resin and clay, the reactivity of the resin and cross-linking agent, as well as the cure temperature and time [8]. In particular, it is often considered to be of primary importance that the intra-gallery cure reaction rate be greater than the extra-gallery rate for exfoliation to occur [9-11]. An important aspect in this context is the use of pre-conditioning (storage of 
the resin/clay mixture for a period of time before adding the curing agent and curing the nanocomposite), when a homopolymerisation reaction takes place within the clay galleries; it has been reported that this aspect of the preparation procedure for the resin/clay mixture can have a very significant effect on the exfoliation process $[12,13]$.

A further complication is that the curing reaction in polymer layered silicate (PLS) nanocomposites based upon epoxy resin and cross-linked with a curing agent is very likely to occur under nonstoichiometric conditions. One reason for this is that the organically modified clay acts as a catalyst for the homopolymerisation of the epoxy resin; another reason is that the curing agent, which is added to the intercalated resin/clay mixture, may not penetrate into the clay galleries, thus creating an off-stoichiometric reaction. As a consequence, the curing reaction does not occur under ideal conditions, to the detriment of the resulting nanostructure.

The objective of this work has been to investigate an alternative method for the non-isothermal cure of PLS nanocomposites based upon an epoxy resin, and in particular on diglycidyl ether of bisphenol A (DGEBA). This alternative approach involves an epoxy homopolymerisation reaction using an anionic initiator. The anionically initiated polymerisation of epoxy monomers is a complex reaction exhibiting two undesirable characteristics: slow reaction rates with long induction periods, and short primary chains due to the high rate of chain-transfer reactions. Dell'Erba and Williams [14] made a study of the anionic polymerisation DGEBA and found that one particular initiator, 4-N,N-dimethylaminopyridine, $\mathrm{C}_{7} \mathrm{H}_{10} \mathrm{~N}_{2}$ (DMAP), can lead to high polymerisation rates and longer primary chains than those generated using other initiators such as tertiary amines and imidazole derivatives. Furthermore, these authors also found that a critical molar ratio DMAP/epoxy groups was necessary in order to obtain complete conversion. Based upon these observations, the aim of the present work is to use DMAP as an initiator of an epoxy homopolymerisation reaction, and to evaluate the influence of the organically modified montmorillonite content on the reaction kinetics and nanostructure and properties of the PLS nanocomposites prepared in this way.

\section{Experimental}

\subsection{Materials}

The epoxy resin used (DER 331, Dow Chemical Company) is a commercial DEGBA resin, with an epoxy equivalent in the range $182-192 \mathrm{~g} \mathrm{eq}^{-1}$ and a viscosity in the range $11,000-14,000 \mathrm{mPa}$. The homopolymerisation reaction was initiated using the anionic initiator, 4-N,N-dimethylaminopyridine, $\mathrm{C}_{7} \mathrm{H}_{10} \mathrm{~N}_{2}$ (DMAP), with a molecular mass of $122.17 \mathrm{~g} / \mathrm{mol}$ and $99 \%$ purity (Panreac). The nanoclay used is a commercial organically modified montmorillonite MMT, trade name Nanomer I.30E, supplied by Nanocor Inc. (Arlington Heights, IL) in which the organic modifier is octadecylamine.

\subsection{Preparation of resin/clay}

Two weight percentages of clay in the resin/clay mixture were used: $2 \mathrm{wt} \%$ and $5 \mathrm{wt} \%$. Initially the nanoclay was dispersed in the resin by hand, followed by $3 \mathrm{~h}$ at $45^{\circ} \mathrm{C}$ in an ultrasonic bath (Branson 3510). Additionally, the samples were vigorously dispersed using a sonicator (Branson S450), in pulse mode and at 30\% amplitude, for a total of $7.5 \mathrm{~min}$, with a programme of 5 separate steps of $1.5 \mathrm{~min}$ each, in which the sample was sonicated in three pulses of $30 \mathrm{~s}$ duration, with 30 s between them. The maximum temperature was limited to $45^{\circ} \mathrm{C}$ by immersing the container, in which the sonication was taking place, in an ice/salt bath and allowing up to $1 \mathrm{~h}$ between the 1.5 min steps for the temperature to reduce sufficiently.
Table 1

Proportions (by weight) of epoxy, DMAP and MMT in nanocomposite samples.

\begin{tabular}{llll}
\hline System & Epoxy & DMAP & MMT \\
\hline EM2 & 98 & 0 & 2 \\
EM5 & 95 & 0 & 5 \\
ED & 97 & 3 & 0 \\
EDM2 & 95 & 3 & 2 \\
EDM5 & 92 & 3 & 5 \\
\hline
\end{tabular}

The quality of the dispersion of the clay in the resin in the different samples was assessed by a Leica DME polarising transmission optical microscope. The resin/clay samples resulting from this mixing procedure are denoted EM2 and EM5 for the $2 \mathrm{wt} \%$ and $5 \mathrm{wt} \%$ clay contents, respectively.

The anionic initiator DMAP, ground to a fine powder, was then added in a proportion of $3 \mathrm{wt} \%$ to the dispersed resin/nanoclay mixtures. Small quantities $(\sim 100 \mathrm{mg})$ were mixed by hand on a watch glass and were then immediately degassed under vacuum, this procedure being repeated for each cure experiment. The nanocomposites with DMAP and $2 \mathrm{wt} \%$ and $5 \mathrm{wt} \%$ clay are denoted, respectively, as EDM2 and EDM5 and are compared with the resin/DMAP system without any clay, denoted as ED. The detailed compositions for all the samples are listed in Table 1.

\subsection{Thermal analysis}

The curing reactions were studied using a Mettler-Toledo DSC 821e differential scanning calorimeter (DSC) equipped with a sample robot and Haake EK90/MT intracooler. All DSC curing experiments were performed with a dry nitrogen gas flow of $50 \mathrm{~mL} \mathrm{~min}^{-1}$. The data evaluation was performed with the STAR software. The DSC was calibrated for both heat flow and temperature using indium. The initiator was added to the epoxy-clay mixture, stirred by hand to ensure a homogeneous mixture, and a small sample of about 8-10 mg was weighed into an aluminium pan, sealed, and immediately inserted into the DSC furnace, whereupon the curing experiment was immediately started.

Non-isothermal scans were made at rates between $2 \mathrm{~K} \mathrm{~min}^{-1}$ and $20 \mathrm{Kmin}^{-1}\left(2,5,10,15\right.$ and $\left.20 \mathrm{Kmin}^{-1}\right)$ over a temperature range from $25^{\circ} \mathrm{C}$ to $280^{\circ} \mathrm{C}$, and followed by a second scan at $10 \mathrm{~K} \mathrm{~min}^{-1}$ to determine the glass transition temperature, $T_{\mathrm{g}}$.

Experiments were also performed using a Mettler-Toledo TGA/DSC1 equipped with a sample robot and Huber cryostat (precision $\pm 0.1^{\circ} \mathrm{C}$ ), which allows the simultaneous measurement of heat flow, by DSC, and weight change of the sample, by thermogravimetric analysis (TGA). The TGA/DSC was calibrated using indium with a dry air flow of $200 \mathrm{~mL} \mathrm{~min}^{-1}$ and the experiments were performed with a dry nitrogen flow of $200 \mathrm{~mL} \mathrm{~min}^{-1}$ at heating rates of $2 \mathrm{~K} \mathrm{~min}^{-1}$ and $10 \mathrm{~K} \mathrm{~min}^{-1}$ over a temperature range from $40{ }^{\circ} \mathrm{C}$ to $600^{\circ} \mathrm{C}$.

\subsection{Transmission electron microscopy}

A Jeol-2011 HRTEM electron microscope was used with an accelerating voltage of $200 \mathrm{kV}$ to characterise the nanostructure of the nanocomposites, which had previously been cured for $3 \mathrm{~h}$ at $70^{\circ} \mathrm{C}$ and post-cured for $3 \mathrm{~h}$ at $120^{\circ} \mathrm{C}$ before the preparation of the sections by ultra-microtomy.

\subsection{Kinetic analysis}

The rate of the reaction in the kinetic analysis can be described as:

$\frac{\mathrm{d} a}{\mathrm{~d} t}=k(T) f(\alpha)$ 
where $k(T)$ is a temperature-dependent reaction rate constant and $f(\alpha)$ is a function that depends on the kinetic model and $\alpha$ is the degree of cure. The temperature dependence of $k(T)$ follows an Arrhenius model:

$k(T)=A \exp \left(-\frac{E}{R T}\right)$

where $A$ is a constant called the pre-exponential factor, $E$ is the activation energy, $R$ is the universal gas constant and $T$ is the absolute temperature. In the DSC experiments, the heat flow $\Phi$ is assumed to be proportional to the rate of cure:

$\Phi=\frac{\mathrm{d} a}{\mathrm{~d} t} \Delta H_{t o t}$

where $\Delta H_{\text {tot }}$ is the total heat of cure of the reaction, which is determined from the area under a non-isothermal DSC curing scan. In this work the empirical two-parameter autocatalytic model (Sesták-Berggren equation) is used:

$f(\alpha)=\alpha^{m}(1-\alpha)^{n}$

where $m$ and $n$ are the kinetic exponents of the reaction. The activation energy $E$ can be determined by the Friedman iso-conversional method [15]. For any given value of $\alpha$, Eqs. (1)-(3) can be combined as:

$\ln [\Phi]=\ln [A f(\alpha)]+\ln \left[\Delta H_{t o t}\right]-\frac{E}{R T}$

Eq. (5) shows that the activation energy can be calculated, for a given value of $\alpha$, from the slope of the logarithm of the heat flow versus the reciprocal temperature, for either isothermal or nonisothermal cure. Once the activation energy has been determined, the other kinetic parameters can be obtained from DSC curves by the method proposed by Málek [16]. This procedure consists of the evaluation of two functions, $y(\alpha)$ and $z(\alpha)$, applicable to both isothermal and non-isothermal experiments, and is used to distinguish between some specific kinetic models. These functions are defined as follows for non-isothermal experiments:

$y(\alpha)=\Delta H_{\text {tot }} A f(\alpha)$

$z(\alpha)=C f(\alpha) g(\alpha)$

where $E / R T$ is a dimensionless quantity later referred to as $x$,

$C=\Delta H_{t o t} \beta\left(\frac{E}{R T}\right)$

and

$g(\alpha)=\int_{0}^{\alpha} \frac{\mathrm{d} \alpha}{f(\alpha)}$

The functions $y(\alpha)$ and $z(\alpha)$ are invariant with respect to the temperature or the heating rate and are sensitive to small changes in the kinetic model $f(\alpha)$. In practice, both $y(\alpha)$ and $z(\alpha)$ are normalized in the interval $\langle 0,1\rangle$ for convenience. The function $y(\alpha)$ is directly proportional to $f(\alpha)$ and the shape of the $y(\alpha)$ function plotted against $\alpha$ provides a direct means for identifying the most appropriate kinetic model. For example, if the maximum in $y(\alpha)$ occurs at $0<\alpha_{\mathrm{M}}<\alpha_{\mathrm{P}}$, where $\alpha_{\mathrm{P}}$ is the value of $\alpha$ at the maximum in the heat flow curve, then the appropriate function is the autocatalytic model given in Eq. (4). It is found in our curing experiments that the autocatalytic model is the most appropriate for the samples studied in this work.

\section{Dielectric measurements}

A dielectric analyser DEA 2970 from TA Instruments was used to measure, in real time, the dielectric signals as a function of frequency during the cure of the epoxy samples. The complex dielectric constant, $\varepsilon^{*}$, may be expressed by a general equation:

$\varepsilon^{*}=\varepsilon^{\prime}-i \varepsilon^{\prime \prime}$

$\tan \delta=\frac{\varepsilon^{\prime \prime}}{\varepsilon^{\prime}}$

where $\varepsilon^{\prime}$ is the dielectric permittivity and $\varepsilon^{\prime \prime}$ is the dielectric loss factor. For epoxy resins with a low ionic concentration, $\varepsilon^{\prime}$ is determined only by the dipolar orientation polarization and $\varepsilon^{\prime \prime}$ is determined by both the ionic conduction and the dipolar reorientation [17]:

$\varepsilon^{\prime}\left(\omega, T_{c}, t_{c}\right)=\varepsilon^{\prime}{ }_{d}\left(\omega, T_{c}, t_{c}\right)$

and

$\varepsilon^{\prime \prime}\left(\omega, T_{c}, t_{c}\right)=\varepsilon^{\prime \prime}{ }_{d}\left(\omega, T_{c}, t_{c}\right)+\varepsilon_{i}^{\prime \prime}\left(T_{c}, t_{c}\right)$

where $\varepsilon^{\prime \prime}{ }_{\mathrm{d}}$ is the dipolar contribution to $\varepsilon^{\prime \prime}, \varepsilon^{\prime \prime}{ }_{i}$ represents the contribution of the dc conductivity to $\varepsilon^{\prime \prime}, \omega$ is the angular frequency ( $\omega=2 \pi f$ ) of the electrical field applied, $f$ is the measuring frequency, and $T_{\mathrm{c}}$ and $t_{\mathrm{c}}$, are the curing temperature and time, respectively. The conductivity is related to the dielectric loss factor by the relation $\sigma=\varepsilon^{\prime \prime} e_{0} \omega$, where $e_{0}$ is the permittivity of free space $\left(8.85 \mathrm{pF} \mathrm{m}^{-1}\right)$. This relation allows the conductivity to be expressed by the contribution of the direct current component $\sigma_{\mathrm{dc}}$, which is attributed to the pure conductive process, and the alternating current component $\sigma_{\mathrm{ac}}$, which is related to the dipolar relaxation:

$\sigma\left(\omega, T_{c}, t_{c}\right)=\sigma_{d c}\left(T_{c}, t_{c}\right)+\sigma_{a c}\left(\omega, T_{c} t_{c}\right)$

Alternatively, $\varepsilon^{*}$ may be expressed in the following form:

$\varepsilon^{*}\left(\omega, T_{c}, t_{c}\right)=\varepsilon_{d}^{\prime}\left(\omega, T_{c}, t_{c}\right)-i \frac{\left[\sigma_{d c}\left(T_{c}, t_{c}\right)+\sigma_{a c}\left(\omega, T_{c}, t_{c}\right)\right]}{\omega \theta_{0}}$

Dielectric measurements were performed using a ceramic single-surface cell with dimensions $20 \mathrm{~mm} \times 25 \mathrm{~mm}$ based on a coplanar inter-digitated comb-like electrode design. The values of $\varepsilon^{\prime}$ and $\varepsilon^{\prime \prime}$ were calculated from the resulting current and the induced phase angle shift. The interval of data sampling was $5 \mathrm{~s}$ per point. The mixture of epoxy-amine was spread on the electrode surface, covering the entire inter-digitated area. The non-isothermal curing measurements were performed at temperatures from $30^{\circ} \mathrm{C}$ to $270{ }^{\circ} \mathrm{C}$ in a nitrogen atmosphere with a gas flow of $500 \mathrm{~mL} \mathrm{~min}^{-1}$. The heating rate was $2 \mathrm{~K} \mathrm{~min}^{-1}$. The dielectric permittivity and the dielectric loss factor were measured at frequencies in the interval from $1 \mathrm{~Hz}$ to $100 \mathrm{kHz}$. The time taken to scan the different frequencies was $1.2 \mathrm{~min}$.

\section{Results and discussion}

As regards the mixtures of resin and clay, there are two aspects to consider: the intercalation of the resin in the clay, and the dispersion of the clay in the resin. Small angle X-ray scattering (SAXS) gives clear evidence that the resin penetrates into the clay galleries, the $d$-spacing increasing from about $2.1 \mathrm{~nm}$ for the organically modified clay to about $3.7 \mathrm{~nm}$ when the epoxy resin is intercalated, essentially independent of the clay content [18]. On the other hand, the dispersion does depend on the clay content. The quality of the dispersion of the $2 \mathrm{wt} \%$ resin/clay mixture is shown in Fig. 1 at various stages in the procedure: (a) initially, after simply mixing the resin and clay by hand; (b) after $3 \mathrm{~h}$ in the ultrasonic bath at $45^{\circ} \mathrm{C}$; (c) after $7.5 \mathrm{~min}$ sonication with the temperature always less than $45^{\circ} \mathrm{C}$. It can be seen that the quality of the dispersion improves with each step of this preparation procedure, but that nevertheless there remain some significant agglomerations of clay in the final mixture. Furthermore, the quality of the dispersion is better for the $2 \mathrm{wt} \%$ mixture than it is for the $5 \mathrm{wt} \%$ mixture, which is shown in 

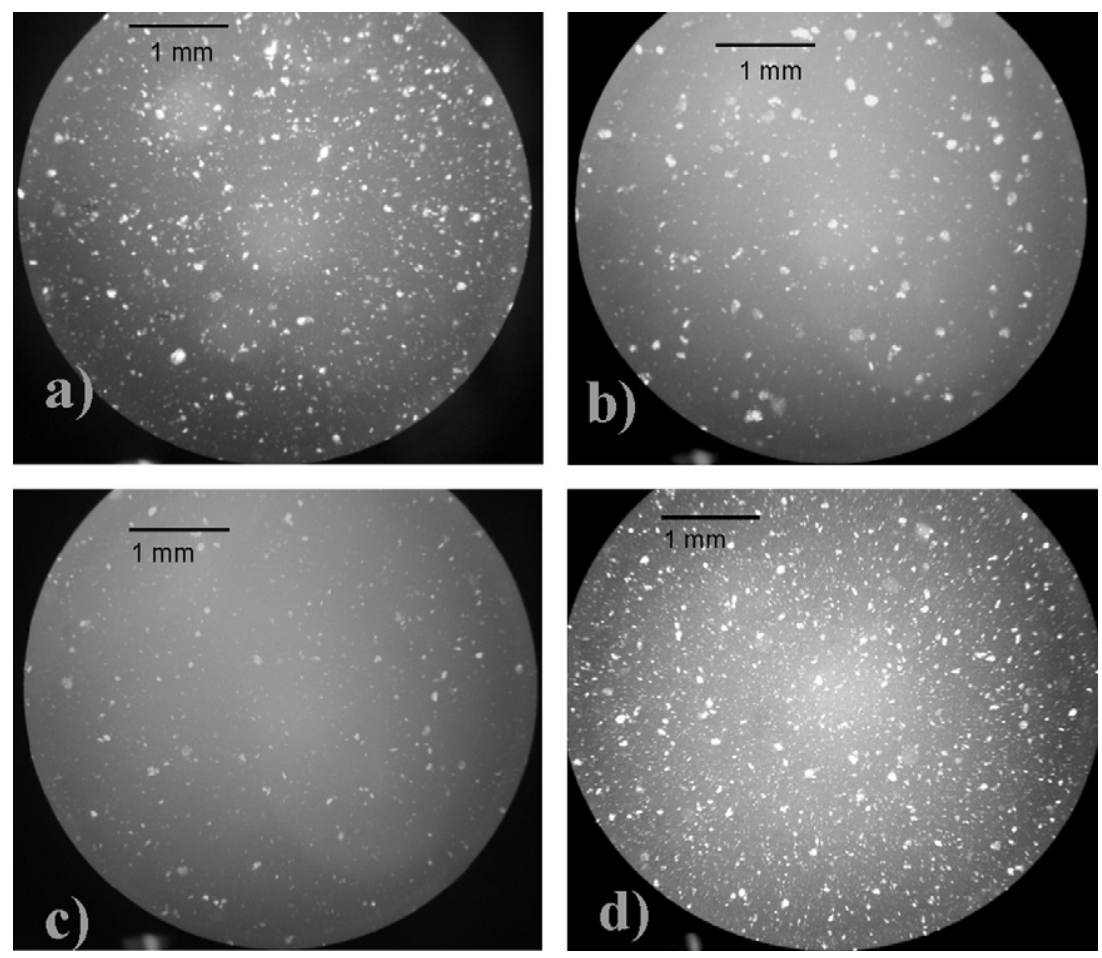

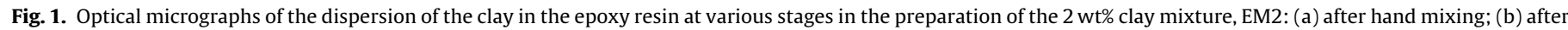

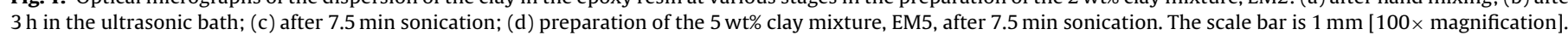

Fig. 1(d). These agglomerations play an important role in the kinetics of the cure reaction, and in the final nanostructure, as will be seen later.

\subsection{Simultaneous $T G A / D S C$}

In order to understand the thermal behaviour of the different components of the nanocomposites, simultaneous TGA/DSC experiments have been carried out. In Fig. 2 the comparative results of three samples are plotted: the first sample is the epoxy resin alone, the second one is the mixture of epoxy resin with $2 \mathrm{wt} \%$ MMT, denoted EM2, and the third is the mixture of epoxy resin, the initiator DMAP and $2 \mathrm{wt} \% \mathrm{MMT}$, denoted EDM2. The exothermic peaks observed in the DSC curves are associated with the homopolymerisation reaction. In the case of the epoxy resin alone, the homopolymerisation reaction appears at temperatures over $400^{\circ} \mathrm{C}$ and is produced thermally [19]. In the sample with epoxy resin and MMT (EM2), the homopolymerisation reaction occurs around $250^{\circ} \mathrm{C}$, and is attributed to the catalytic effect of the organically modified clay [18]. And finally, in the sample EDM2 the homopolymerisation reaction can be seen to take place at even lower temperatures as a consequence of the effect of the anionic initiator, DMAP. At the same time, the TGA curves show that the effect of homopolymerisation in EM2, which begins at around $200^{\circ} \mathrm{C}$, is to stabilise the sample thermally in comparison with the epoxy alone, while the anionically initiated homopolymerisation in EDM2 is even more effective in this respect. Finally, there is evidence of degradation of sample EDM2 at around $430^{\circ} \mathrm{C}$.

\subsection{Differential scanning calorimetry (DSC) data}

The cure kinetics studies are based on DSC experiments. Fig. 3 shows the non-isothermal DSC thermograms of ED, EDM2 and EDM5 at different heating rates. The temperature $\left(T_{\mathrm{p}}\right)$ at which the peak of the heat flow occurs is lower for EDM2 than for both ED and EDM5. On the other hand, $T_{\mathrm{p}}$ for EDM5 is higher than that for ED except at the highest heating rates of 15 and $20 \mathrm{~K} \mathrm{~min}^{-1}$ (EDM2 $<$ ED $\leq$ EDM5). In all these systems, at heating rates lower than $15 \mathrm{~K} \mathrm{~min}^{-1}$ an intense peak is observed followed by a shoulder at the end of the exothermic process. At higher heating rates, the exothermic peak has a slightly asymmetric shape.

The total heat of reaction $\Delta H_{\text {tot }}$ for the three different samples and for the different heating rates is plotted in Fig. 4. The total heat of reaction is obtained from the heat of reaction evaluated

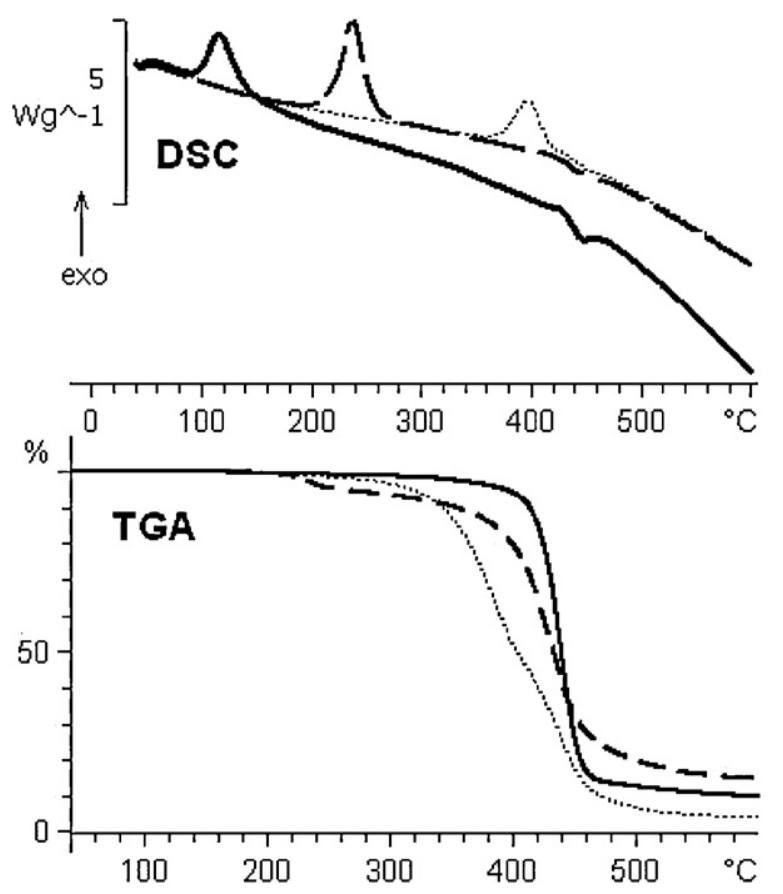

Fig. 2. Simultaneous TGA/DSC at $10 \mathrm{Kmin}^{-1}$ of epoxy alone (...), EM2 (-), EDM2 $(-)$. 


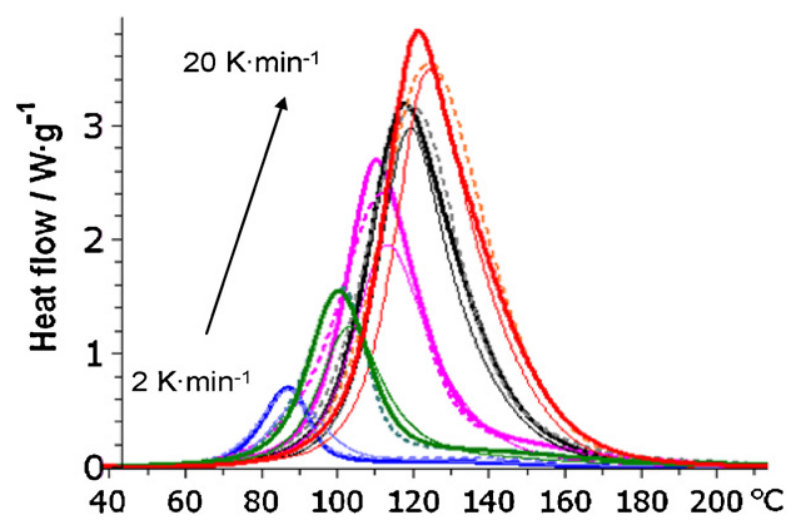

Fig. 3. Non-isothermal DSC thermograms of ED (dashed line), EDM2 (thick line) and EDM5 (thin line) at the following rates (from bottom to top): 2, 5, 10, 15 and $20 \mathrm{~K} \mathrm{~min}^{-1}$.

during the first scan, because no residual heat of cure during the second scan was observed. It can be seen that in all samples the total heat of reaction decreases as the heating rate increases. This effect is not uncommon, and has previously been reported, for example, for thermosetting polyesters [20], amine cured epoxy resins $[21,22]$ and catalysed epoxy-anhydride systems [23], as well as being observed earlier in amine cured epoxy PLS nanocomposites analogous to the system studied here [12]. In this last work it was hypothesised that the reduction in the heat of reaction as the clay content increased might be attributable to the difference in the heat of reaction for those reactions occurring via the primary and secondary amines compared with those occurring via homopolymerisation, as has been reported by other authors [14,24]. Our hypothesis here is that an increased amount of thermally induced homopolymerisation occurs at the higher heating rates, and that this reaction involves a lower heat of reaction in comparison with those involving the secondary amine. For a given heating rate, it can be seen that EDM5 has the lowest total heat of reaction, while ED and EDM2 have similar values.

In the subsequent second scan at $10 \mathrm{~K} \mathrm{~min}^{-1}$, the glass transition temperature of the cured nanocomposite is determined. In Fig. 5 the glass transition temperature of the three different nanocomposites is plotted as a function of the heating rate. It can be observed that the glass transition temperature increases slightly with increasing heating rate for EDM2, whereas it decreases significantly for EDM5. In the sample without clay, ED, the value of the glass transition temperature is intermediate between those for EDM5 and EDM2. This suggests that the cured EDM2 system could have a higher cross-linking density than for EDM5, probably due to a better dispersion of the clay in the resin, as shown in Fig. 1 [1], or it may be intrinsically due to the clay dispersion, leading to decreased

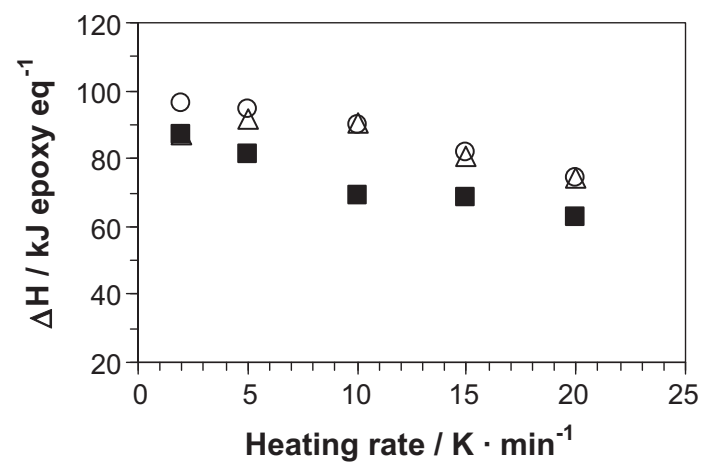

Fig. 4. Total heat of reaction versus the heating rate for three systems: $\operatorname{ED}(\bigcirc)$, $\operatorname{EDM} 2$ $(\Delta), \operatorname{EDM} 5(\boldsymbol{\square})$.

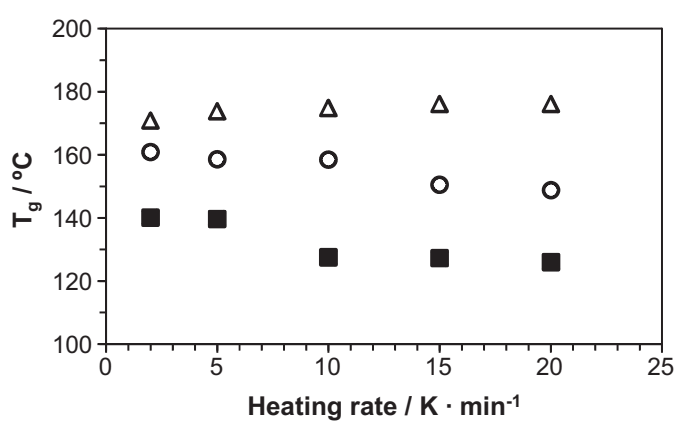

Fig. 5. Glass transition temperature versus heating rate obtained from the second scan for $\operatorname{ED}(\bigcirc)$, $\operatorname{EDM} 2(\Delta)$ and $\operatorname{EDM} 5(\boldsymbol{\square})$

mobility of the resin; similar dispersion effects on the glass transition temperature have been reported for thermoplastic nanocomposites [25,26], while a decrease in $T_{\mathrm{g}}$ with increasing clay content has been reported for other epoxy/clay nanocomposites [27]. The value of $T_{\mathrm{g}}$ of about $160^{\circ} \mathrm{C}$ for the cured epoxy in the absence of any clay (sample ED) is in good agreement with the results reported by Dell'Erba and Williams [14].

It is interesting to speculate why a higher cross-link density (chemical network) might be associated with a better dispersion of the clay. We believe that, within the agglomerations which preponderate in the higher ( $5 \mathrm{wt} \%$ ) clay content sample, EDM5, the epoxy resin does not have easy access to the DMAP initiator, and thus must react by a thermally initiated homopolymerisation process. Furthermore, these agglomeration regions are confined within the bulk of the sample, which cures more readily by a DMAP initiated homopolymerisation, and which shrink on cure, resulting in not only a confinement but also a compression of the agglomerations; evidence for this is available from Transmission Electron Microscopy, where the $d$-spacing of numerous clay layers is found to be less than that of the intercalated clay after the resin-clay mixing process [12]. The implication is that the cross-linking is inhomogeneous in samples such as EDM5 in which there is a significant number of large agglomerations: dense cross-linking within the agglomerations and hence less dense cross-linking in the bulk. The corollary of this is that samples with a better dispersion, such as EDM2 here, have a higher density of cross-linking in the bulk, and hence a higher value of $T_{\mathrm{g}}$.

\subsection{Activation energy and kinetic analysis}

In order to perform the kinetic analysis, it was necessary first to deconvolute the asymmetric peaks or the peaks with high temperature shoulders, shown in Fig. 3, using the Peakfit program. In the EDM2 and EDM5 systems, the exothermic curves have been deconvoluted into two peaks for all the heating rates used here; the first peak is more intense than the second peak, as illustrated in Fig. 6 for the cases of EDM2 and EDM5 cured at 10 and $20 \mathrm{~K} \mathrm{~min}^{-1}$, respectively (Fig. $6 \mathrm{~b}$ and c). On the other hand, in the ED system, the first peak is present for all heating rates while the second peak was observed only for the lower heating rates, below $15 \mathrm{~K} \mathrm{~min}^{-1}$, as shown in Fig. 6(a) for a heating rate of $2 \mathrm{~K} \mathrm{~min}^{-1}$. The second peak can be attributed to a devitrification effect of the system $[28,29]$. Vitrification occurs when $T_{\mathrm{g}}$ increases up to the cure temperature. While continuing the heating, the $T_{\mathrm{g}}$ will keep increasing, following the continuous increase in reaction temperature. When the conversion approaches unity, the reaction and the $T_{\mathrm{g}}$ increase slow down, and as the cure temperature passes $T_{\mathrm{g}}$, the system devitrifies. During the vitrification process the cure reaction is dramatically slowed down, but then will proceed again to completion after the system devitrifies at higher temperature. The occurrence of these 

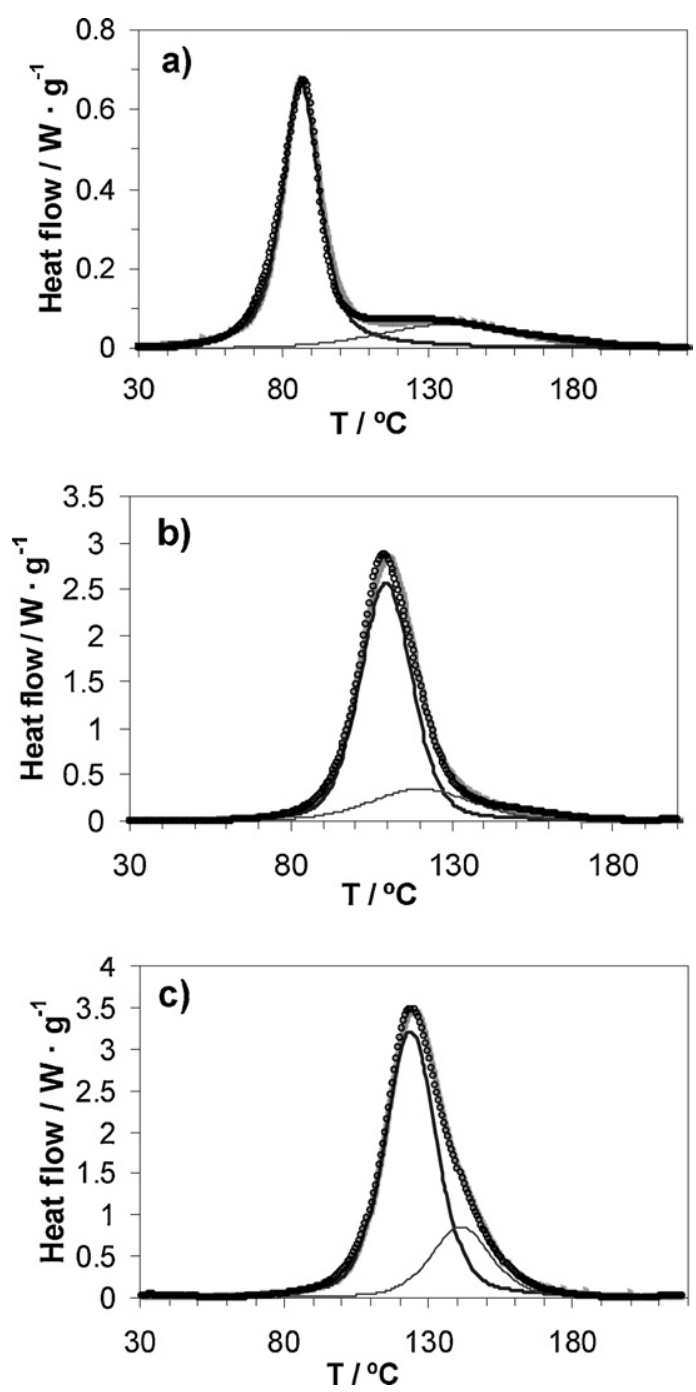

Fig. 6. Deconvolution of the exothermic peak for samples cured non-isothermally: (a) ED at $2 \mathrm{~K} \mathrm{~min}^{-1}$, (b) EDM2 at $10 \mathrm{Kmin}^{-1}$, (c) EDM5 at $20 \mathrm{~K} \mathrm{~min}^{-1}$. Experimental data $(\bigcirc)$, fit (full line), first peak (dark line), second peak (thin line).

processes of vitrification and devitrification is favoured at slower heating rates, hence their observation here only for rates below $15 \mathrm{~K} \mathrm{~min}^{-1}$

The similar attribution of the second peak in samples EDM2 and EDM5 to a process of devitrification might seem appropriate, but it must be borne in mind that there may be other processes occurring in these systems in which there is organically modified clay present. In particular, there may be two homopolymerisation reaction mechanisms: the first one could be attributed to a reaction initiated by the DMAP, while the second one could be due to a thermally induced reaction which is catalysed by the ammonium ion content in the organically modified clay [19]. These possibilities are reflected in the DSC thermograms in Fig. 6, showing the homopolymerisation due to the DMAP occurring at significantly lower temperature than that catalysed by the MMT. Furthermore, at the slower heating rates, between 2 and $10 \mathrm{~K} \mathrm{~min}^{-1}$, the second peak is much more significant in EDM5 than in EDM2, implying a greater degree of thermal homopolymerisation in the former. An explanation for this could lie in the nanostructure: the poorer dispersion of the clay in sample EDM5 would result in there being a greater proportion of epoxy resin intercalated in the clay galleries and without access to the DMAP, and hence for which the only
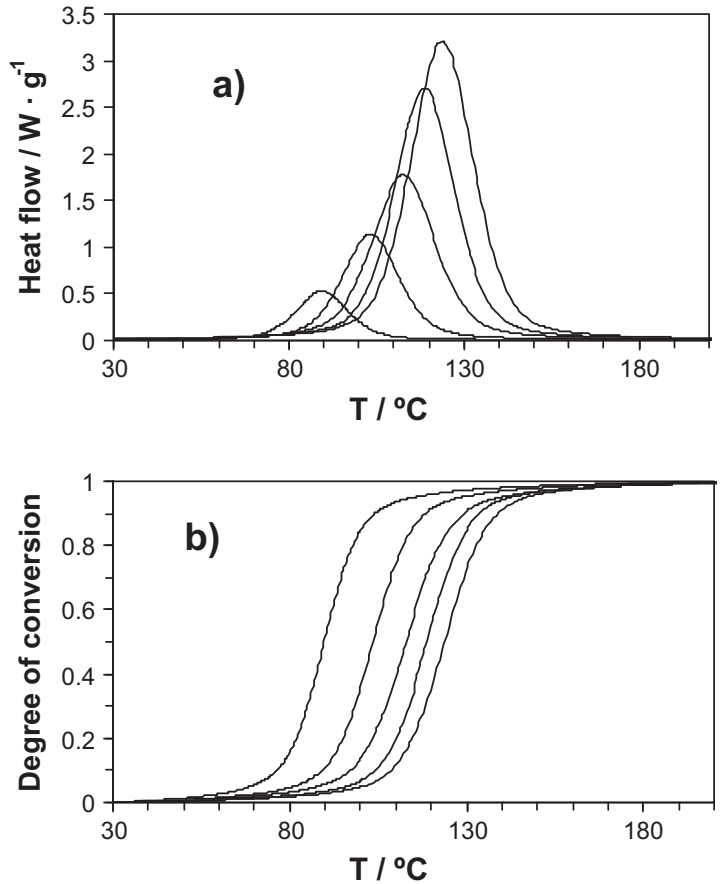

Fig. 7. Homopolymerisation reaction based on the first peak at heating rates of 2,5 , 10 , and $20 \mathrm{~K} \mathrm{~min}^{-1}$ : (a) exothermic peak (in order from bottom to top); (b) evolution of the degree of conversion (in order from left to right) for the EDM5 system.

reaction possible is thermally induced homopolymerisation. This explanation is consistent with the observation (Fig. 4) that the heat of reaction is reduced for sample EDM5.

As the nanostructure of the nanocomposite is influenced by the reaction kinetics, it is important to establish precisely what is the nature of these two peaks. From the above discussion, it is apparent that DSC is not able to distinguish clearly between devitrification and homopolymerisation processes. On the other hand, we show later that Dielectric Relaxation Spectroscopy can be illuminating in this respect, after first describing the kinetic analysis of the DSC data.

The kinetic study was based on the first peak, which is associated with the homopolymerisation catalysed by the DMAP. The degree of conversion $(\alpha)$ was determined by considering only the heat of reaction of this first peak, obtained by deconvolution of the cure curves in Fig. 6. Fig. 7(a) shows, for the EDM5 system, the exothermic reaction attributed to the homopolymerisation reaction due to the effect of the initiator DMAP at different heating rates, while Fig. 7(b) gives, for the same system, the degree of conversion as a function of temperature during the cure.

The activation energy calculated by the isoconversional method [30] from the non-isothermal cure data is obtained from the plot of the logarithm of the heat flow, corresponding to fixed values of $\alpha$, usually in the intervals from 0.1 to 0.9 , versus the reciprocal of the temperature (at which the sample has achieved a given value of $\alpha$ at any selected heating rate $\beta$ ) [15]. The values of activation energy are calculated from the slopes of these plotted lines, according to Eq. (5), for which a fair linear relationship is obtained. In Fig. 8, the resulting values of the isoconversional activation energy for each of the systems studied are plotted as a function of the degree of cure. It can be seen from this figure that the activation energies for ED and EDM2 display both very similar values and also a similar trend as a function of the degree conversion, while the EDM5 exhibits somewhat higher values and a different behaviour. We take the following average isoconversional activation energies, determined over the range of $\alpha$ from 0.2 


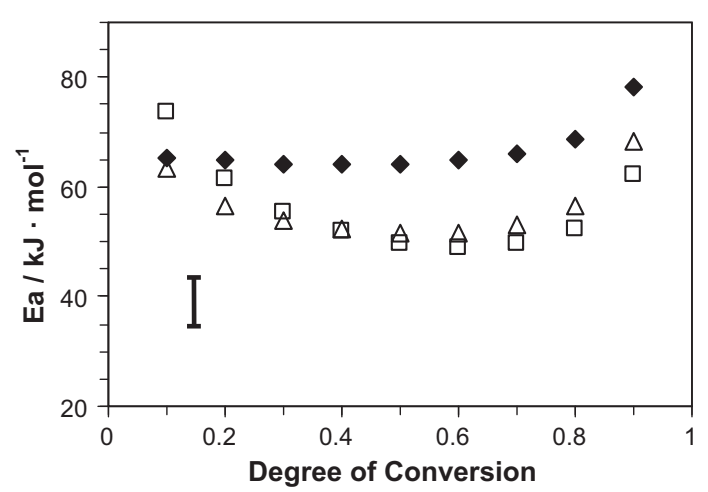

Fig. 8. Isoconversional activation energy versus degree of conversion for ED ( $\square$ ), EDM2 $(\Delta)$, EDM5 $(\downarrow)$. The error bar indicates a 70\% confidence interval.

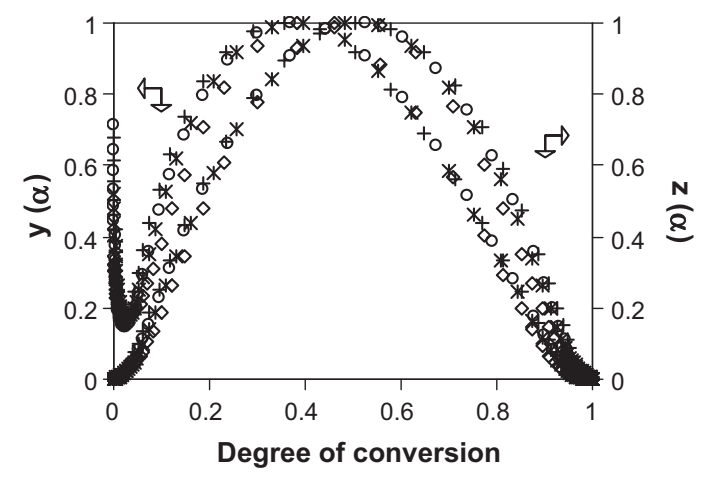

Fig. 9. Normalized $y(\alpha)$ and $z(\alpha)$ functions in the interval $\langle 0,1\rangle$, as a function of $\alpha$ during non-isothermal cure at $2(\diamond), 5\left(^{*}\right), 15(+)$, and $20 \mathrm{~K} \mathrm{~min}^{-1}(\bigcirc)$ for sample EDM2.

to 0.8 , with the uncertainty calculated for a $70 \%$ confidence interval based upon the Student $t$ distribution: ED $56.2 \pm 6.7 \mathrm{~kJ} \mathrm{~mol}^{-1}$; EDM2 $56.3 \pm 6.8 \mathrm{~kJ} \mathrm{~mol}^{-1}$, EDM5 $66.8 \pm 8.0 \mathrm{~kJ} \mathrm{~mol}^{-1}$.

Once the activation energy has been evaluated, both $y(\alpha)$ and $z(\alpha)$ can be calculated from Eqs. (6) and (7). As an illustration, Fig. 9 shows the normalized $y(\alpha)$ and $z(\alpha)$ functions for one of the samples studied here, namely EDM2, at the different heating rates used. The values of $\alpha_{\mathrm{M}}$ and $\alpha_{\mathrm{P}}{ }^{\infty}$, which are the values of $\alpha$ when $y(\alpha)$ and $z(\alpha)$, respectively, pass through their maximum values, together with $\alpha_{\mathrm{p}}$, which is the value of $\alpha$ at the maximum of the DSC cure exotherm, are listed for all three samples in Table 2 . The values of $\alpha_{\mathrm{M}}$ are lower than those of $\alpha_{\mathrm{P}}$, whereas $\alpha_{\mathrm{P}}{ }^{\infty}$ exhibits values lower than 0.632 . This indicates that all the studied curing systems can be

Table 2

Values of $\alpha_{\mathrm{P}}, \alpha_{\mathrm{M}}$ and $\alpha_{\mathrm{P}}{ }^{\infty}$ determined from DSC data for ED, EDM2 and EDM5 samples.

\begin{tabular}{lrlll}
\hline System & Heating rate $\left[\mathrm{Kmin}^{-1}\right]$ & $\alpha_{\mathrm{P}}$ & $\alpha_{\mathrm{M}}$ & $\alpha_{\mathrm{P}}{ }^{\infty}$ \\
\hline ED & 2 & 0.508 & 0.389 & 0.508 \\
ED & 5 & 0.511 & 0.408 & 0.512 \\
ED & 10 & 0.509 & 0.332 & 0.510 \\
ED & 15 & 0.506 & 0.332 & 0.510 \\
ED & 20 & 0.506 & 0.290 & 0.506 \\
EDM2 & 2 & 0.498 & 0.385 & 0.46 \\
EDM2 & 5 & 0.499 & 0.394 & 0.482 \\
EDM2 & 10 & 0.503 & 0.389 & 0.523 \\
EDM2 & 15 & 0.503 & 0.357 & 0.503 \\
EDM2 & 20 & 0.498 & 0.369 & 0.525 \\
EDM5 & 2 & 0.499 & 0.409 & 0.499 \\
EDM5 & 5 & 0.477 & 0.391 & 0.477 \\
EDM5 & 10 & 0.505 & 0.357 & 0.505 \\
EDM5 & 15 & 0.507 & 0.350 & 0.508 \\
EDM5 & 20 & 0.496 & 0.345 & 0.496 \\
\hline
\end{tabular}

Table 3

Kinetic parameters evaluated for ED, EDM2 and EDM5 samples.

\begin{tabular}{lllll}
\hline System & $m$ & $n$ & $n+m$ & $\ln \left[A / \mathrm{s}^{-1}\right]$ \\
\hline ED & 1.0 & 1.7 & 2.7 & 14.2 \\
EDM2 & 1.2 & 2.0 & 3.2 & 14.9 \\
EDM5 & 1.2 & 2.0 & 3.2 & 15.0 \\
\hline
\end{tabular}

described with a two-parameter autocatalytic kinetic model given by the Séstak-Berggren Equation (4) [31,32].

The parameters $n$ and $m$ are the kinetic exponents. The value of $n$ is obtained from the slope of the linear dependence of $\ln \left[(\mathrm{d} \alpha / \mathrm{d} t) \mathrm{e}^{x}\right]$ versus $\ln \left[\alpha^{P}(1-\alpha)\right]$ where $x=E / R T$ and $p=\alpha_{M} /\left(1-\alpha_{M}\right)$, and then the value of $m$ is determined from the relationship $m=p n$. The kinetic parameters $m$ and $n$ for the autocatalytic model have been evaluated for all systems studied and for each heating rate, and the averages are presented in Table 3.

The suitability of the kinetic model proposed, based on the autocatalytic equation, is verified by comparing the experimental results for $\mathrm{d} \alpha / \mathrm{d} t$ as a function of temperature with the theoretical curves, which have been obtained with the help of TAS software [16]. Fig. 10 presents this comparison for all three systems studied. It can be seen that theory and experiment are in good agreement, implying that the autocatalytic kinetic model is well suited for the kinetic analysis of all these curing systems.

\subsection{Dielectric relaxation spectroscopy (DRS) results}

In the samples EDM2 and EDM5, two peaks are observed in the deconvoluted DSC exotherms at different heating rates (e.g. see Fig. 6): the first one, more well-defined and larger, is due to the homopolymerisation of the epoxy, initiated by the DMAP; the second peak could result from a devitrification process or it might be associated with a thermally induced homopolymerisation, catalysed by the ammonium ion of the organically modified clay. In the system ED (without clay), the second peak, which occurs for heating rates below $15 \mathrm{~K} \mathrm{~min}^{-1}$, can be ascribed to a phenomenon of vitrification-devitrification of the system [28,29]. In order to explain the origin of the second peak in the exotherms for the nanocomposite samples in which the homopolymerisation was initiated by DMAP, a dielectric analysis has been carried out on the samples ED and EDM2 with the purpose of comparing their responses.

For both the ED and EDM2 samples, in the $\tan \delta$ curves at temperatures below $50^{\circ} \mathrm{C}$, a first peak can be observed in Fig. 11 for the frequency of $100 \mathrm{~Hz}$, while only the high temperature flank of such a peak is observed for the lower frequencies of 1 and $10 \mathrm{~Hz}$. This peak, whose nature is dipolar, shifts to higher temperature with increasing frequency as a consequence of the decrease of the characteristic relaxation time for molecular segments $\left\langle\tau_{0}\right\rangle$ $\left(\left\langle\tau_{0}\right\rangle=(2 \pi f)^{-1}\right)$ [33-35], and corresponds to the $\alpha$-relaxation, associated with the glass transition of the uncured epoxy. It finishes when the cross-linking reaction begins at about $50^{\circ} \mathrm{C}$, as shown in the relaxation map in Fig. 12.

Immediately following the $\alpha$-relaxation, the phenomenon associated with the cross-linking reaction of the system takes place in the wide region between $50^{\circ} \mathrm{C}$ and $230^{\circ} \mathrm{C}$, again for both $\mathrm{ED}$ and EDM2 samples. Within the narrower range of temperatures from $50{ }^{\circ} \mathrm{C}$ to $100^{\circ} \mathrm{C}$, the permittivity $\varepsilon^{\prime}$, the loss factor $\varepsilon^{\prime \prime}$ and the ionic conductivity all pass through a maximum (these signals are not shown here, for simplicity, but will be analysed separately in more detail in a subsequent publication), which decreases in intensity as the frequency increases, but which is invariant in position at approximately $70^{\circ} \mathrm{C}$. This maximum corresponds to a degree of conversion of approximately $7 \%(\alpha \approx 0.07)$, as found from the results for the degree of conversion determined from DSC 

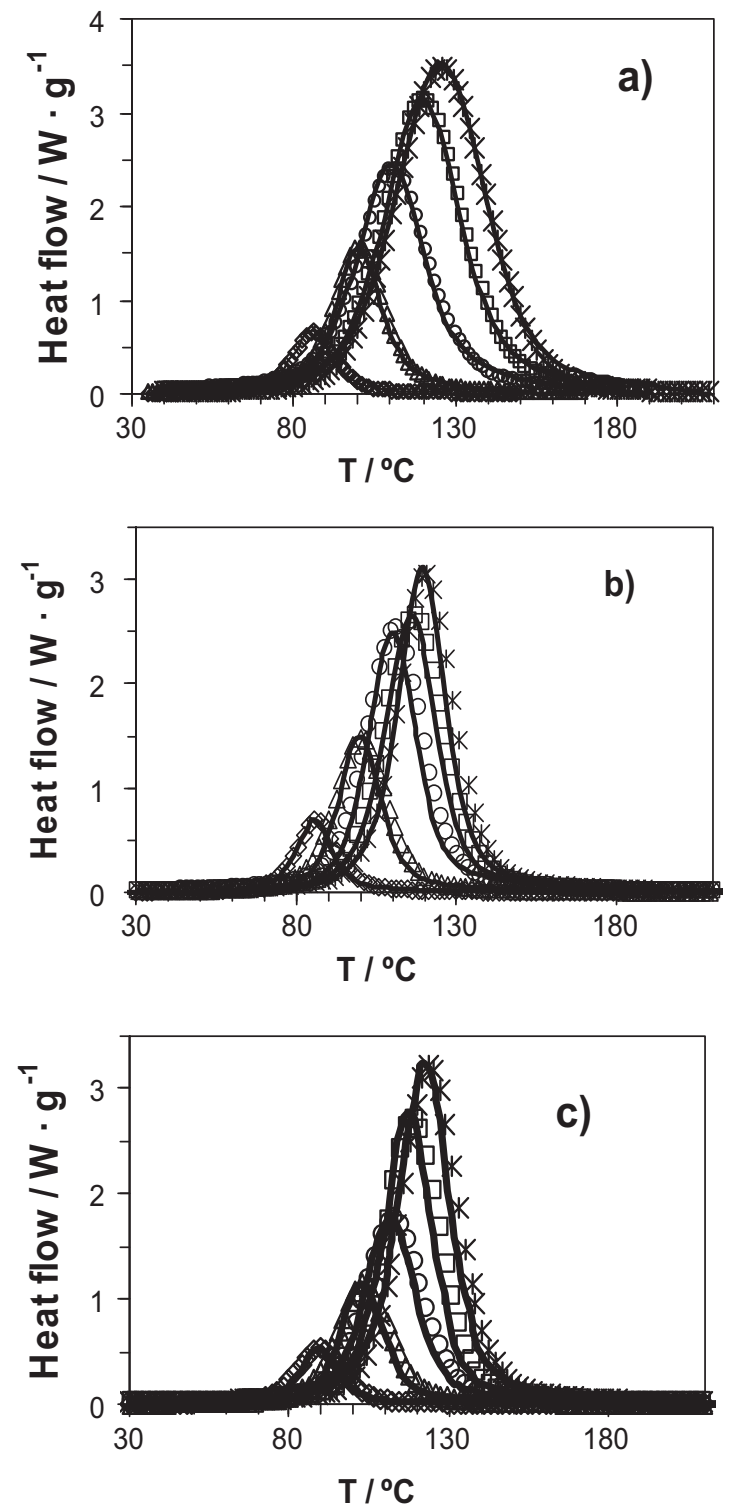

Fig. 10. Comparison of experimental and theoretical curves for the three systems studied: (a) ED, (b) EDM2 and (c) EDM5. Data points represent experimental results for heating rates $\left(\mathrm{K} \mathrm{min}^{-1}\right)$ of $2(\diamond), 5(\Delta), 10(\bigcirc), 15(\square)$ and $20\left(^{*}\right)$; the full lines represent fit of theoretical model.

experiments at a heating rate of $2 \mathrm{~K} \mathrm{~min}^{-1}$. On the other hand, as can be seen in Fig. 11(a) for sample ED, in the $\tan \delta$ signal a second dipolar relaxation peak, denoted $\alpha_{1}$, appears in the range between $70^{\circ} \mathrm{C}$ and $100^{\circ} \mathrm{C}$, for frequencies lower than $0.5 \mathrm{kHz}$, the maximum of this peak shifting to higher temperatures when the frequency decreases. It is remarkable that the temperature at which the maximum of $\tan \delta$ occurs for $f>0.5 \mathrm{kHz}$ coincides with that of the minimum of $\tan \delta$ observed between the $\alpha$-relaxation (associated with the glass transition) and the $\alpha_{1}$-relaxation for $f<0.5 \mathrm{kHz}$, as seen in the relaxation map of Fig. 12. The shift of the peak temperature of the $\alpha_{1}$-relaxation to higher temperatures as the frequency decreases is a consequence of an increase of the relaxation time $<$ $\tau_{0}>$ resulting from a higher degree of conversion. At the same time, as shown earlier [33], $\varepsilon^{\prime}$ decreases with increasing temperature and with increasing degree of conversion, indicating that this relaxation is associated with the vitrification phenomenon.

After the maximum of the $\alpha_{1}$-relaxation, $\tan \delta$ decreases towards a minimum value which is reached at about $100-105^{\circ} \mathrm{C}$, and which corresponds to a degree of conversion of $0.90-0.95$ as
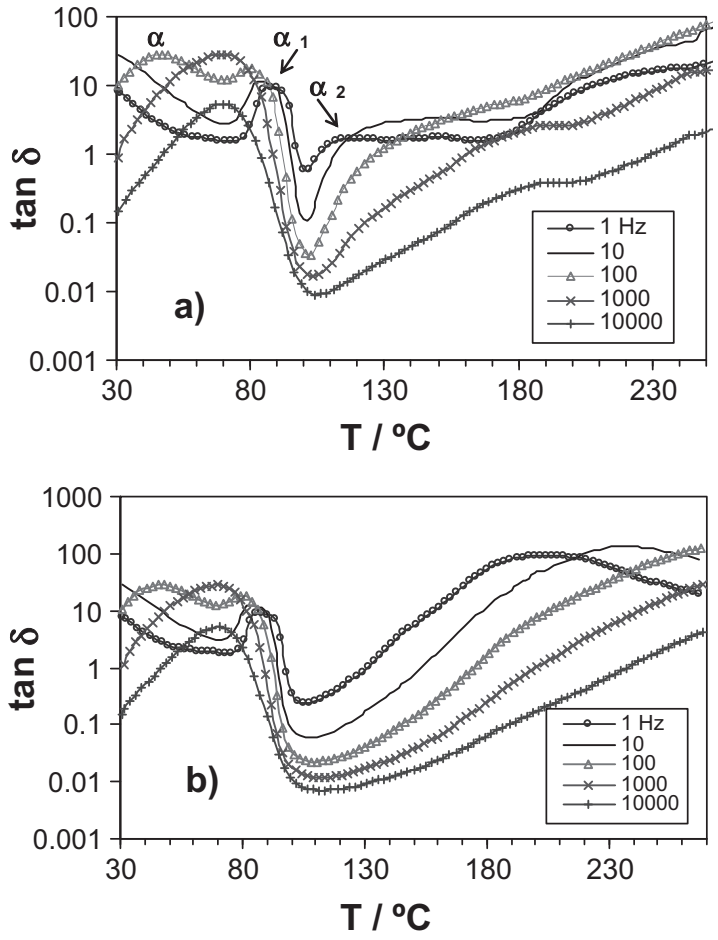

Fig. 11. Variation of $\tan \delta$, during the curing of (a) ED and (b) EDM2 at a heating rate of $2 \mathrm{Kmin}^{-1}$ and frequencies measured in the range between $1 \mathrm{~Hz}$ and $10,000 \mathrm{~Hz}$. Relaxations $\alpha, \alpha_{1}$, and $\alpha_{2}$, associated with the glass transition, vitrification and devitrification, respectively, are indicated.

determined by DSC studies at a heating rate of $2 \mathrm{~K} \mathrm{~min}^{-1}$. With a further increase of temperature, a wide shoulder denoted as the $\alpha_{2}$ relaxation is observed in the $\tan \delta$ signal for the ED sample, as seen in Fig. 11(a). This shoulder shifts to higher temperatures as the frequency increases $\left(112^{\circ} \mathrm{C}\right.$ for $f=1 \mathrm{~Hz}, 119^{\circ} \mathrm{C}$ for $f=10 \mathrm{~Hz}, 129^{\circ} \mathrm{C}$ for $f=100 \mathrm{~Hz}$ and $180^{\circ} \mathrm{C}$ for $f=1 \mathrm{kHz}$, and remains invariant for higher frequencies), and is plotted on the relaxation map in Fig. 12. Taking into account that the characteristic relaxation time $\left\langle\tau_{0}\right\rangle$ of this dipolar relaxation decreases with increasing frequency when the temperature increases, this shoulder can be associated with the devitrification of the system. This observation is in agreement with the non-isothermal curing of a diepoxy-cycloaliphatic diamine system (3,3'-dimethyl-4,4'-diaminodicyclohexyl-methane, 3DCM) [33] and accords also with the earlier interpretation of the DSC results (Fig. 3). The $\tan \delta$ signal for EDM2 is similar to that of the

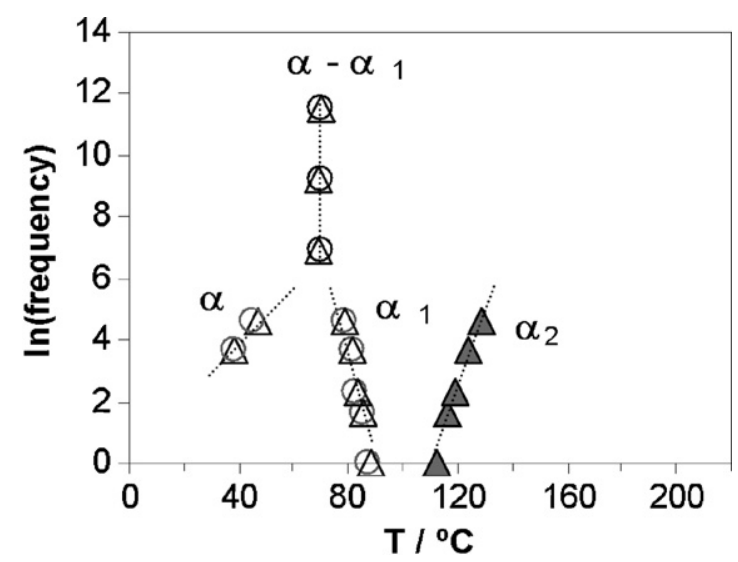

Fig. 12. Temperatures of the relaxation peaks $\alpha, \alpha_{1}$ and $\alpha_{2}$ measured at different frequencies in the $\tan \delta$ spectra of samples $\operatorname{ED}(\Delta)$ and $\operatorname{EDM} 2(\bigcirc)$ for the heating rate of $2 \mathrm{~K} \mathrm{~min}^{-1}$. 


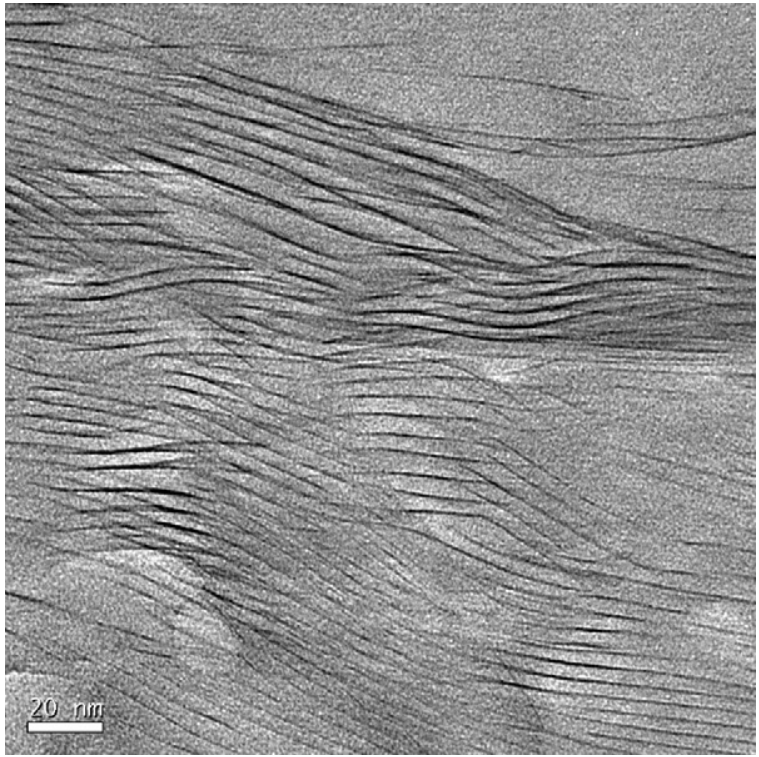

Fig. 13. Nanostructure of sample EDM2 observed by TEM.

ED sample in the range from 30 to $100^{\circ} \mathrm{C}$, as shown in Fig. 11 (b): the dipolar relaxation peak $\alpha_{1}$ shifts to higher temperatures when the frequency decreases, this relaxation being associated with the vitrification of the resin, in the same way as for the ED sample.

For temperatures up to $100^{\circ} \mathrm{C}$, therefore, the relaxation behaviour of the sample EDM2 is similar to that of the sample ED. There are significant differences between ED and EDM2, however, at higher temperatures. Most importantly, for the sample EDM2, the $\alpha_{2}$-relaxation associated with devitrification is not observed in the $\tan \delta$ signal. The reason for this is that, in sample EDM2, the devitrification results in an increase in the resin reactivity, occurring simultaneously with the devitrification, and being associated with a homopolymerisation reaction catalysed by the ammonium ion of the clay. A consequence is that the resin remains longer in the vitrified state, since devitrification shifts closer to $T_{g_{\infty}}$. This further reaction continues until a conversion degree of $100 \%$ is reached. For temperatures higher than $180^{\circ} \mathrm{C}$ in the sample EDM2, a peak appears in $\tan \delta$. This peak shifts $\left(202^{\circ} \mathrm{C}\right.$ at $1 \mathrm{~Hz}, 236^{\circ} \mathrm{C}$ at $\left.10 \mathrm{~Hz}\right)$ to higher temperature with increasing frequency, indicating that it has a dipolar nature, and is associated with (though not an accurate measure of) the glass transition of the fully cured material. For the reason stated above, the devitrification shifts close to $T_{\mathrm{g}_{\infty}}$, and hence this peak is some convolution of the devitrification and the glass transition, which may explain why the shift with frequency, about $30 \mathrm{~K}$ for one decade difference in frequency, is some 5 times greater than normally observed for a glass transition. In the calorimetric measurements performed at the same heating rate of $2 \mathrm{~K} \mathrm{~min}^{-1}$, a glass transition can be observed at $170-175^{\circ} \mathrm{C}$ for the fully cured material (Fig. 5). These DSC and DRS results are therefore in qualitative agreement; the DRS glass transition occurs at higher temperatures than for DSC because the frequency is higher.

The DRS measurements therefore detect, for the sample EDM2 containing $2 \mathrm{wt} \%$ clay, a homopolymerisation reaction, thermally induced, which is superimposed on the devitrification process, and which does not appear for the sample ED without clay. This homopolymerisation, which takes place at temperatures much higher than those associated with the homopolymerisation reaction catalysed by the DMAP, occurs within the clay galleries of the agglomerations of clay that persist after the mixing process (see Fig. 1), which are regions to which the DMAP has not been able to penetrate. This relaxation is therefore associated with the quality of the dispersion of the clay. Indeed it is found, from our
DSC cure experiments, that the magnitude of this second peak in the deconvoluted heat flow curve, is greater for sample EDM5 than for EDM2 at low heating rates, which is consistent with the observation that the dispersion is better for sample EDM2 than for sample EDM5 (see Fig. 1). Furthermore, this would imply that more thermally induced homopolymerisation is occurring for sample EDM5, which is consistent with the lower heat of reaction found for this system (see Fig. 4).

The important implication of these observations is that a better nanostructure would be anticipated for EDM2 than for EDM5, and this is exactly what is observed from Transmission Electron Microscopy (TEM) observations. Fig. 13 shows a TEM micrograph of the nanostructure within one of the agglomerations of sample EDM2, where it can be seen that, although there remain some clay layers with spacings of about $4 \mathrm{~nm}$, there is clear evidence of substantial exfoliation and disorganisation of the layer stacking, particularly at the outer limits of the agglomeration, corresponding to the region at the top of Fig. 13.

\section{Conclusions}

The non-isothermal reaction kinetics for the cure of polymer layered silicate nanocomposites based upon epoxy resin with an anionic initiator DMAP have been studied by means of differential scanning calorimetry (DSC) and dielectric relaxation spectroscopy (DRS). The DSC results indicate that the organically modified clay catalyses the curing reaction. A kinetic model based upon an autocatalytic reaction mechanism provides a good fit to the nonisothermal DSC data. The presence of montmorillonite in epoxy resin does not change the autocatalytic nature of reaction, but the activation energy of the curing process increases as the montmorillonite content increases.

The addition of $2 \mathrm{wt} \%$ clay (EDM2) advances the reaction compared with the system without clay (ED) while 5 wt\%(EDM5) delays the reaction. The glass transition temperature, $T_{\mathrm{g}}$, of the fully cured system EDM2 is significantly higher than that of ED, while that of EDM5 is significantly lower. Additionally, the comparison of the heats of reaction in these systems indicates that complete reaction of the epoxy occurs for $2 \mathrm{wt} \%$ clay, whereas the reaction is inhibited for the system with 5 wt\% clay.

In all systems, the cure curve shows the existence of a second relaxation, which has the appearance of a devitrification process. This is particularly evident at low heating rates, but the cure curve can be deconvoluted into two peaks for all heating rates.

The DRS results associated with the molecular mobility of the polymeric chain during the curing process reveal the relaxation attributed to the vitrification-devitrification effect for both systems. This effect is clearly evident in the system ED, while in the system EDM2 the devitrification is masked by the simultaneous occurrence of a thermally induced homopolymerisation reaction of the epoxy resin, catalysed by the onium ion of the clay. This implies that the second peak or shoulder observed by DSC is associated with devitrification in sample ED but is predominantly due to homopolymerisation of the intra-gallery epoxy resin in the samples containing clay, and is more pronounced in sample EDM5 than in EDM2, leading to a reduced heat of reaction in the former. From this we conclude that the nanostructure of the sample containing $2 \mathrm{wt} \%$ clay should be the better, and this is confirmed by Transmission Electron Microscopy observations.

\section{Acknowledgements}

Financial support has been provided by the Spanish Ministry, CICYT (MAT2008-06284-C03-03) and MICINN (MAT2011-27039C03-03). The authors are grateful to the Dow Chemical Company for the provision of the epoxy resin DER331. 


\section{References}

[1] D.R. Paul, L.M. Robeson, Polymer nanotechnology: nanocomposites, Polymer 49 (2008) 3187-3204.

[2] M.T. Ton-That, T.D. Ngo, P. Ding, G. Fang, K.C. Cole, S.V. Hoa, Epoxy nanocomposites: analysis and kinetics of cure, Polym. Eng. Sci. 44 (2004) 1132-1141.

[3] J.M. Brown, D. Curliss, R.A. Vaia, Thermoset-layered silicate nanocomposites. Quaternary ammonium montmorillonite with primary diamine cured epoxies, Chem. Mater. 12 (2000) 3376-3384.

[4] M. Alexandre, P. Dubois, Polymer-layered silicate nanocomposites: preparation, properties and uses of a new class of materials, Mater. Sci. Eng. 28 (2000) $1-63$.

[5] S.S. Ray, M. Okamoto, Polymer/layered silicate nanocomposites: a review from preparation to processing, Prog. Polym. Sci. 28 (2003) 1539-1641.

[6] O. Becker, G.P. Simon, Epoxy layered silicate nanocomposites, Adv. Polym. Sci. 179 (2005) 29-82.

[7] W.B. Xu, Z.F. Zhou, P.S. He, W.P. Pan, Cure behavior of epoxy resin/MMT/DETA nanocomposite - resin curemeter, J. Therm. Anal. Calorim. 78 (2004) $113-124$.

[8] F. Roman, S. Montserrat, J.M. Hutchinson, On the effect of montmorillonite in the curing reaction of epoxy nanocomposites, J. Therm. Anal. Calorim. 87 (2007) $113-118$.

[9] X. Kornmann, H. Lindberg, L.A. Berglund, Synthesis of epoxy-clay nanocomposites: influence of the nature of the clay on structure, Polymer 42 (2001) 1303-1310.

[10] W.B. Xu, S.P. Bao, P.S. He, Intercalation and exfoliation behavior of epoxy resin/curing agent/montmorillonite nanocomposite, J. Appl. Polym. Sci. 84 (2002) 842-849.

[11] J.H. Park, S.C. Jana, Mechanism of exfoliation of nanoclay particles in epoxy-clay nanocomposites, Macromolecules 36 (2003) 2758-2768.

[12] S. Montserrat, F. Roman, J.M. Hutchinson, L. Campos, Analysis of the cure of epoxy based layered silicate nanocomposites: reaction kinetics and nanostructure development, J. Appl. Polym. Sci. 108 (2008) 923-938.

[13] T. Benson Tolle, D.P. Anderson, The role of preconditioning on morphology development in layered silicate thermoset nanocomposites, J. Appl. Polym. Sci. 91 (2004) 89-100.

[14] I.E. Dell'Erba, R.J.J. Williams, Homopolymerization of epoxy monomers initiated by 4-(dimethylamino)pyridine, Polym. Eng. Sci. 46 (2006) 351-359.

[15] H.L. Friedman, Kinetics of thermal degradation of char-forming plastics from thermogravimetry. Application to phenolic plastic, J. Polym. Sci. Part C 6 (1964) $183-195$.

[16] J. Málek, The kinetic analysis of non-isothermal data, Thermochim. Acta 200 (1992) 257-269.

[17] S.D. Senturia, N.F. Sheppard, Dielectric analysis of thermoset cure, Adv. Polym. Sci. 80 (1986) 1-47.

[18] J.M. Hutchinson, S. Montserrat, F. Román, P. Cortés, L. Campos, Intercalation of epoxy resin in organically modified montmorillonite, J. Appl. Polym. Sci. 102 (2006) 3751-3763.
[19] K.C. Cole, A new approach to modelling the cure kinetics of epoxy amine thermosetting resins. 1. Mathematical development, Macromolecules 24 (1991) 3093-3097.

[20] J.M. Salla, J.L. Martin, Dynamic, isothermal and residual heats of curing of an unsaturated polyester resin, Thermochim. Acta 126 (1988), 339-354.21.

[21] R.A. Fava, Differential scanning calorimetry of epoxy resins, Polymer 9 (1968) 137-151.

[22] J.M. Kenny, A. Trivisano, M.E. Frigione, L. Nicolais, Thermal-analysis of standard and toughened high-performance epoxy matrices, Thermochim. Acta 199 (1992) 213-227.

[23] S. Montserrat, G. Andreu, P. Cortés, Y. Calventus, P. Colomer, J.M. Hutchinson, J. Malek, Addition of a reactive diluents to a catalyzed epoxy-anhydride system. I. Influence on the cure kinetics, J. Appl. Polym. Sci. 61 (1996) 1663-1674.

[24] C.H. Klute, W. Viehmann, Heat of polymerization of phenyl glycidyl ether and of an epoxy resin, J. Appl. Polym. Sci. 5 (1961) 86-95.

[25] P. Rittigstein, J.M. Torkelson, Polymer-nanoparticle interfacial interactions in polymer nanocomposites: confinement effects on glass transition temperature and suppression of physical aging, J. Polym. Sci. B Polym. Phys. 44 (2006) 2935-2943.

[26] A. Bansal, H. Yang, C. Li, K. Cho, B.C. Benicewicz, S.K. Kumar, L.S. Schadler, Quantitative equivalence between polymer nanocomposites and thin polymer films, Nat. Mater. 4 (2005) 693-698.

[27] M.G. Prolongo, F.J. Martínez-Casado, R.M. Masegosa, C. Salom, Curing and dynamic mechanical thermal properties of epoxy/clay nanocomposites, J. Nanosci. Nanotechnol. 10 (2010) 2870-2879.

[28] I. Fraga, S. Montserrat, J.M. Hutchinson, Vitrification, Devitrification during the non-isothermal cure of a thermoset. Theoretical model and comparison with calorimetric experiments, Macromol. Chem. Phys. 211 (2010) 57-65.

[29] I. Fraga, S. Montserrat, J.M. Hutchinson, Vitrification and devitrification during the non-isothermal cure of a thermoset, J. Thermal Anal. Calorim. 99 (2010) 925-929.

[30] S. Vyazovkin, N. Sbirrazzuoli, Isoconversional kinetic analysis of thermally stimulated processes in polymers, Macromol. Rapid Commun. 27 (2006) 1515-1532.

[31] J. Málek, Kinetic analysis of crystallization processes in amorphous materials, Thermochim. Acta 355 (2000) 239-253.

[32] S. Montserrat, J. Málek, A kinetic analysis of the curing reaction of an epoxyresin, Thermochim. Acta 228 (1993) 47-60.

[33] S. Montserrat, F. Roman, P. Colomer, Vitrification, devitrification, and dielectric relaxations during the non-isothermal curing of diepoxy-cycloaliphatic diamine, J. Appl. Polym. Sci. 102 (2006) 558-563.

[34] E. Tombari, G. Salvetti, G.P. Johari, The temperature and polymerization effects on the relaxation time and conductivity, and the evolution of the localized motions, J. Chem. Phys. 113 (2000) 6957-6965.

[35] C. Cardelli, E. Tombari, G.P. Johari, The combined effects of temperature and polymerization rate changes on the real-time conduction and relaxation of a liquid, and the evolution of localized motions, J. Phys. Chem. B 105 (2001) 11035-11043. 